\title{
Anaplasma phagocytophilum infects cells of the megakaryocytic lineage through sialylated ligands but fails to alter platelet production
}

\begin{abstract}
Correspondence
Dori L. Borjesson

dlborjesson@ucdavis.edu
\end{abstract}

Received 2 August 2007

Accepted 21 December 2007
Jennifer L. Granick, ${ }^{1}$ Dexter V. Reneer, ${ }^{2}$ Jason A. Carlyon ${ }^{3}$ and Dori L. Borjesson ${ }^{4}$

\author{
${ }^{1}$ Department of Veterinary Clinical Sciences, College of Veterinary Medicine, University of \\ Minnesota, St Paul, MN, USA \\ ${ }^{2}$ Department of Microbiology, Immunology and Molecular Genetics, University of Kentucky College \\ of Medicine, Lexington, KT, USA \\ ${ }^{3}$ Department of Microbiology and Immunology, Virginia Commonwealth University School of \\ Medicine, Richmond, VA, USA \\ ${ }^{4}$ Department of Pathology, Microbiology and Immunology, School of Veterinary Medicine, Davis, CA, \\ USA
}

\begin{abstract}
Anaplasma phagocytophilum is an obligate intracellular bacterial pathogen that principally inhabits neutrophils. However, infection with $A$. phagocytophilum results in a moderate to marked thrombocytopenia. In host neutrophils, $A$. phagocytophilum uses sialylated ligands, primarily $\mathrm{P}$ selectin glycoprotein ligand-1 (PSGL-1), to enter its host cell. PSGL-1 is expressed on a wide array of haematopoietic cells, including megakaryocytes. In this study, it was hypothesized that (i) cells of the megakaryocytic lineage (MEG-01 cells) would be susceptible to A. phagocytophilum infection and (ii) infection may induce alterations in platelet production contributing to infectioninduced thrombocytopenia. It was found that MEG-01 cells are susceptible to infection. MEG-01 cells expressing abundant sialylated ligands were the most susceptible to infection, and the absence of sialylation, or blocking of PSGL-1, limited infection susceptibility. However, infected MEG-01 cells produced proplatelets and platelet-like particles comparable to uninfected cells. These results highlight a novel target of pathogen infection and suggest that the pathogen may utilize similar strategies to gain access to megakaryocytes. Direct pathogen modification of platelet production may not play a role in infection-induced thrombocytopenia.
\end{abstract}

\section{INTRODUCTION}

Anaplasma phagocytophilum, an obligate intracellular bacterium, is the causative agent of granulocytic anaplasmosis (GA), formerly known as granulocytic ehrlichiosis (Chen et al., 1994; Dumler et al., 2001). GA is an emerging, zoonotic, tick-borne disease spread by Ixodes spp. tick vectors. Regardless of host species, infection with $A$. phagocytophilum results in hallmark haematological alterations, most notably a moderate to marked thrombocytopenia (Bakken et al., 1996, 2001; Borjesson et al., 2001). Thrombocytopenia may be accompanied by a mild to moderate leukopenia and mild anaemia (Bakken et al., 1996; Borjesson et al., 2001; Madigan \& Gribble, 1987; Pusterla et al., 1999). The mechanism of thrombocytopenia and other cytopenias is unknown.

Abbreviations: FBS, fetal bovine serum; GA, granulocytic anaplasmosis; MK, megakaryocyte; p.i., post-infection; PLPs, platelet-like particles; PSGL-1, P-selectin glycoprotein-1; sLe ${ }^{\mathrm{x}}$, sialyl Lewis $\mathrm{x}$.
A. phagocytophilum primarily infects host neutrophils. However, it is also capable of infecting other haematopoietic and non-haematopoietic cells including human bone marrow-derived CD34 ${ }^{+}$cells (Klein et al., 1997) and endothelial cells (Munderloh et al., 2004). Pathogen infection of human neutrophils has been shown to occur through binding of P-selectin glycoprotein ligand-1 (PSGL-1) and sialylated and $\alpha 1,3$-fucosylated glycans such as the sialyl Lewis $\mathrm{x}\left(\mathrm{sLe}^{\mathrm{x}}\right)$ antigen (Goodman et al., 1999; Herron et al., 2000). Specifically, $\mathrm{sLe}^{\mathrm{x}}$ is important for A. phagocytophilum invasion (Goodman et al., 1999) and the PSGL-1 N-terminal peptide is important for both bacterial binding and internalization (Herron et al., 2000). We have recently shown that $A$. phagocytophilum can also adhere to and infect host myelocytic cells in a sialic acid- and PSGL-1independent manner (Reneer et al., 2006; Sarkar et al., 2007). A variety of haematopoietic cells express PSGL-1, including platelets and their progenitor cells, megakaryocytes (MKs) (Frenette et al., 2000). Combined, these data suggest that other haematopoietic cells, notably MKs, may be 
susceptible to A. phagocytophilum infection via bacterial interactions with $\mathrm{sLe}^{\mathrm{x}}$ and PSGL-1. Infection of haematopoietic precursors may contribute to infection-induced cytopenias.

Mammalian platelets are anucleate cells, derived from MKs, that carry out little de novo protein synthesis. Platelets are produced by mature, differentiated MKs in the bone marrow where long, cytoplasmic processes (proplatelets) are extended into marrow sinusoids (Italiano et al., 1999). MK cell lines are often employed for studies on platelet production. The leukaemic megakaryoblastic cell line MEG-01 has been shown to produce proplatelets and platelet-like particles (PLPs) in cell culture (Takeuchi et al., 1998). Additionally, these cells can be induced towards differentiation and maturation using various agents including phorbol-12-myristate-13-acetate, an anti-Fas antibody (CH11) and thrombopoietin (Battinelli et al., 2001; Clarke et al., 2003; Ogura et al., 1988).

The purpose of this study was to assess the susceptibility of MEG-01 cells to A. phagocytophilum infection and to evaluate further the pathogen effects on proplatelet formation and platelet production. We hypothesized that MEG-01 cells would be susceptible to infection and that infection might alter platelet production and thus contribute to infectioninduced thrombocytopenia. Our findings suggest that MK lineage cells are indeed susceptible to A. phagocytophilum infection. However, infection does not significantly alter proplatelet formation or platelet production.

\section{METHODS}

Megakaryocytic cell line culture. A human megakaryocytic cell culture line (MEG-01 cells) was obtained from ATCC and propagated in RPMI 1640 (Invitrogen) containing 10\% heat-inactivated fetal bovine serum (FBS) and $2 \mathrm{mM} \mathrm{L}$-glutamine. Cells were maintained at $37{ }^{\circ} \mathrm{C}$ with $5 \% \mathrm{CO}_{2}$ as described by Ogura et al. (1985).

Growth of bacteria and infection of MEG-01 cells with $A$. phagocytophilum. A. phagocytophilum (NCH-1 isolate; Goodman et al., 1996; Telford et al., 1996) was maintained in the human promyelocytic cell line (HL60 cells) as described previously (Borjesson et al., 2005b). In brief, HL60 cells were cultured in Iscove's modified Dulbecco's medium (HyClone) containing $20 \%$ heat-inactivated FBS at $37{ }^{\circ} \mathrm{C}$ with $5 \% \mathrm{CO}_{2}$. A. phagocytophilum was harvested from infected HL60 cells as described previously (Borjesson et al., 2005b), resuspended in RPMI 1640 and immediately inoculated into MEG-01 cell cultures $\left(5 \times 10^{5}\right.$ cells $\left.\mathrm{ml}^{-1}\right)$. Cells were evaluated for infection daily by cytofuge preparation and Protocol Hema3 staining (ThermoFisher Scientific). For infection kinetics experiments, DNA encoding the primary outer-membrane protein of $A$. phagocytophilum ( $p 44$ ) was quantified using real-time PCR (ABI Prism 7700 Sequence Detector; Applied Biosystems) as described previously (Borjesson et al., 2002).

Electron microscopy. Infected and uninfected MEG-01 cells $\left(3 \times 10^{6}\right)$ were pelleted in a microfuge at 1200 r.p.m. for 5 min. Cells were fixed in $2 \mathrm{ml} 2.5 \%$ glutaraldehyde in PBS (pH 7.4) for $2 \mathrm{~h}$. The cells were washed three times in PBS for 5-10 min each, pelleted at 1200 r.p.m. for 5 min and fixed in $1 \%$ osmium tetroxide in PBS for $5 \mathrm{~min}$. The samples were then processed for electron microscopy as described by White (2005).

Flow cytometric detection of MEG-01 cell-surface receptors. Uninfected MEG-01 cells $\left(1 \times 10^{5}\right)$ were diluted in buffer $(1.0 \%$ FBS in PBS). Cells were incubated with PL1 (215 antibody, mouse IgG2a; Santa Cruz Biotechnology), CSLEX1 (mouse IgM; BD Biosciences), PL2 (rat IgM; BD Biosciences) or the respective isotype-matched controls for $30 \mathrm{~min}$ (all at $10 \mu \mathrm{g} \mathrm{ml}^{-1}$ ) at room temperature. The cells were washed once and incubated with FITC- or phycoerythrinconjugated goat anti-mouse $\operatorname{IgG}$, anti-mouse IgM or anti-rat IgM in the dark for $30 \mathrm{~min}$ at room temperature. The cells were washed once and resuspended in buffer containing $1 \%$ paraformaldehyde. All samples were analysed on a FACSCanto flow cytometer (BD Biosciences) using CellQuest software.

PL1 blocking. Infected MEG-01 cells $\left(5 \times 10^{5}\right)$ were plated in 12-well tissue culture plates and diluted with uninfected MEG-01 cells until their infection burden was $5 \%$, as assessed by stained cytofuge preparations. MEG-01 cells were incubated for $1 \mathrm{~h}$ with either no antibody (positive control), a blocking antibody to PSGL-1 (2 $\mu \mathrm{g}$ PL1 $\mathrm{ml}^{-1}$; Ancell) or the isotype-matched control (anti-mouse IgG1). All conditions were run in triplicate. The cells were washed twice, a time 0 sample was obtained and the remaining wells were incubated at $37{ }^{\circ} \mathrm{C}$ with $5 \% \quad \mathrm{CO}_{2}$. The infection burden was monitored by cytofuge preparation and quantitative PCR (to detect A. phagocytophilum p44 DNA) on days 0,3 and 5 post-infection (p.i.).

RT-PCR for gene expression. Total RNA was isolated from cultured MEG-01 cells as described previously (Borjesson et al., 2005b). In brief, $600 \mu \mathrm{l}$ RLT buffer (Qiagen; containing $10 \mu \mathrm{l}$ 2-mercaptoethanol $\mathrm{ml}^{-1}$ ) was added directly to the wells containing MEG-01 cells. The samples were mixed by pipetting and transferred to $1.5 \mathrm{ml}$ RNase-free Eppendorf tubes. Samples were further homogenized by centrifugation in QIAshredder spin columns (Qiagen) at $18000 \mathrm{~g}$, followed by RNA isolation using an RNeasy mini kit (Qiagen). Samples were treated with DNase (Invitrogen). DNA digestion was confirmed by RT-PCR with primers targeting human $\beta$-actin in the presence and absence of reverse transcriptase. Samples were normalized for total RNA concentrations using TaqMan $\beta$-actin detection reagents (Applied Biosystems) on a MyiQ Single-Colour Real-Time PCR Detection System (Bio-Rad). cDNA was generated from normalized RNA samples using a SuperScript III First-strand Synthesis System for RT-PCR (Invitrogen). cDNA samples were used as templates in PCRs targeting human sialyl transferases, $\alpha 1,3$-fucosyltransferases, PSGL- 1 and $\beta$-actin, as described previously (Reneer et al., 2006).

MEG-01 induction and proliferation. MEG-01 cells were induced to differentiate using CH11 (anti-Fas agonistic monoclonal antibody; Upstate Biotechnology) (Chuang \& Schleef, 2001; Clarke et al., 2003; Ogura et al., 1988). In brief, MEG-01 cells were plated in 12-well tissue culture plates (Corning Costar) at a final concentration of $3 \times 10^{5}$ cells per well. Cells were incubated with $\mathrm{CH} 11\left(50 \mathrm{ng} \mathrm{ml}^{-1}\right)$ for $8-96 \mathrm{~h}$.

The proliferation of MEG-01 cells in response to A. phagocytophilum infection was examined. Cell-free $A$. phagocytophilum was inoculated into induced $(72 \mathrm{~h}$ ) and uninduced MEG- 01 cells (ratio of $2: 1$, infected HL60 cells : MEG-01 cells, 20-50 A. phagocytophilum per MEG-01 cell), as described previously (Borjesson et al., 2005b). Plates were centrifuged at $380 \mathrm{~g}$ for $8 \mathrm{~min}$ to synchronize bacterial uptake (Borjesson et al., 2005b). Culture plates were incubated at $37{ }^{\circ} \mathrm{C}$ in a humidified incubator with $5 \% \mathrm{CO}_{2}$ for up to $96 \mathrm{~h}$. Plates were sampled at 24, 48, 72 and $96 \mathrm{~h}$ p.i. In order to collect all cells, non-adherent cells and medium supernatant were collected, after which $100 \mu$ trypsin/ $/ 0.25 \%$ EDTA (Invitrogen) was added to the wells and allowed to incubate for 2-4 min. The supernatant was then returned to the well, the well 
contents were mixed, and all cells and medium were removed. Wells were washed with PBS and visualized using an inverted microscope to assure complete cell collection. Cells were gently vortexed and aliquots were removed for counting using a haemocytometer. Samples were run in triplicate. Counts were repeated and the mean calculated.

MEG-01 proplatelet formation and platelet production. Platelet production by MEG-01 cells was evaluated in two steps: enumerating the intermediate proplatelet phenotype and enumerating functional platelet yield (Chuang \& Schleef, 2001; Clarke et al., 2003; Ogura et al., 1988). In brief, infected and uninfected MEG-01 cells were transferred to tissue culture plates (Corning Costar) at a low density $\left(4 \times 10^{4}\right.$ cells $\left.\mathrm{ml}^{-1}\right)$. Cells were visualized every $24 \mathrm{~h}$ until cells in infected wells were at least $40-50 \%$ infected. Half of the infected and half of the uninfected wells were induced to differentiate with $\mathrm{CH} 11$. The total number of proplatelet-bearing MEG-01 cells per 500 cells (as indicated by distinctive thin cytoplasmic processes) was enumerated using phase microscopy on an inverted microscope at $24 \mathrm{~h}$ post-induction (Clarke et al., 2003). Proplatelet formation was compared between infected and uninfected, and between induced and uninduced MEG-01 cells.

Platelet production from MEG-01 cells was enumerated as described previously by Battinelli et al. (2001), Clarke et al. (2003) and Takeuchi et al. (1998) with minor alterations. Culture supernatants containing platelets from infected and uninfected MEG-01 cells were fixed in the wells with $1 \%$ paraformaldehyde (Sigma-Aldrich) for $30 \mathrm{~min}$. The well contents were collected and separated by centrifugation at $300 \mathrm{~g}$ for 2 min to pellet the MEG-01 cells, leaving the platelets in the supernatant. The number of MEG-01 cells was determined using a haemocytometer at the time of platelet enumeration. The supernatant was then centrifuged at $300 \mathrm{~g}$ for $15 \mathrm{~min}$ and resuspended in $100 \mu \mathrm{l}$ PBS. Platelets were stained with $25 \mu \mathrm{l}$ mouse anti-human mAb to detect $\alpha_{\mathrm{IIb}}$ of the $\alpha_{\mathrm{IIb}} \beta_{3}\left(\mathrm{GPII}_{\mathrm{b}} \mathrm{III}_{\mathrm{a}}\right)$ platelet integrin complex (phycoerythrin-conjugated CD41; Ancell). For accurate enumeration, suspended platelets were mixed with TruCount beads (BD Biosciences) according to the manufacturer's instructions. All samples were analysed on a FACSCanto flow cytometer using CellQuest software. Platelets were gated on characteristic forward and side scatter and on positive CD41 expression.
Statistical analysis. Statistical analysis was performed using Student's $t$-test (Microsoft Excel 2002). A $P$ value of $<0.05$ was considered significant.

\section{RESULTS AND DISCUSSION}

\section{A. phagocytophilum infects a human megakaryocytic cell line}

Host-cell tropism has been a defining biological feature of pathogens in the family Anaplasmataceae. Members of this family infect monocytes (e.g. Ehrlichia chaffeensis, Ehrlichia muris and Ehrlichia canis), granulocytes (e.g. A. phagocytophilum and Ehrlichia ewingii), red blood cells (Anaplasma marginale) and platelets (Anaplasma platys). Recently, potential host cells have expanded to include endothelial cells (Munderloh et al., 2004), early haematopoietic precursor cells, CD34 ${ }^{+}$cells (Klein et al., 1997) and haematopoietic precursors differentiated along granulocytic and monocytic lineages (Klein et al., 1997).

In our study, A. phagocytophilum readily infected megakaryoblastic MEG-01 cells (Fig. 1a, b). Infection kinetics, as assessed by visualization and quantitative PCR, paralleled pathogen growth kinetics in the human myelocytic HL60 cells (Fig. 1c). Our findings expand the host-cell range for this pathogen to include cells of the megakaryocyte lineage and suggest the potential for a broad array of susceptible host cells in the bone marrow. Indeed, in the mouse model of infection, bone marrow is consistently infected as measured by quantitative PCR (Hodzic et al., 2001). Given the cytopenias associated with this disease, even passing infection of cells within the haematopoie-

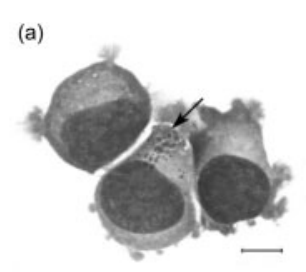

(C)

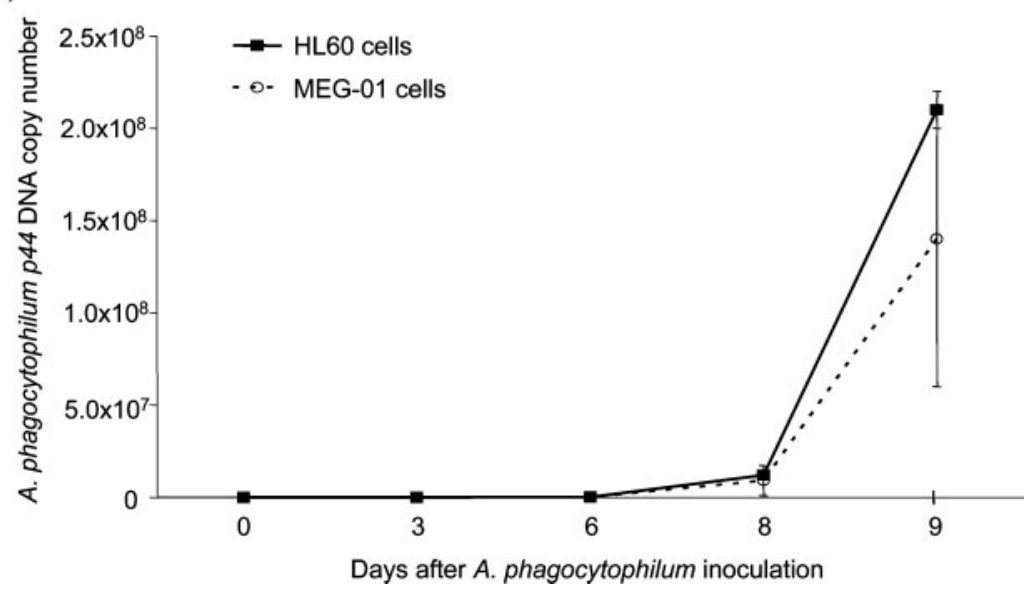

Fig. 1. A. phagocytophilum infects cells of the megakaryocytic lineage (MEG-01). (a) Cytofuge smear of MEG-01 cells with intracellular bacterial colonies (morulae, arrow; stained with Protocol Hema-3). Bar, $0.01 \mathrm{~mm}$. (b) Electron micrograph of an $A$. phagocytophilum-infected MEG-01 cell. The arrows depict typical bacterial colonies with individual bacteria forming a morula structure within a cytoplasmic vacuole. A, cell nucleus. Bar, $5.0 \mu \mathrm{m}$. (c) Kinetics of bacterial replication in MEG-01 cells. Quantitative PCR for the bacterial outer-membrane protein p44 gene showed that bacterial replication in MEG-01 cells parallels that in the prototype human granulocytic leukaemia cell line HL60. 
tic microenvironment may alter cell proliferation and differentiation.

\section{A. phagocytophilum uses siaylated ligands for optimal infection}

The ability of $A$. phagocytophilum to bind and enter host myeloid cells has been associated with host-cell surface expression of PSGL-1 and sialylated and $\alpha 1,3$-fucosylated glycans including sLe $^{\mathrm{x}}$ antigen (Goodman et al., 1999; Herron et al., 2000; Yago et al., 2003). Optimal host-cell infection occurs with the cooperative binding of at least two bacterial adhesins to these receptors (Yago et al., 2003). As such, we assessed the surface expression of PSGL-1 on MEG01 cells. Initial flow cytometric analysis of MEG-01 cellsurface receptors revealed moderate to high surface expression of PSGL-1 using mAb PL1 (Fig. 2a). PL1 blocks A. phagocytophilum binding to human PSGL-1 N terminusmodelled glycopeptides and to PSGL-1 on human neutrophil and HL60 cell surfaces (Herron et al., 2000; Li et al., 1996; Yago et al., 2003). Likewise, PL1 successfully blocked $A$. phagocytophilum infection of MEG-01 cells (Fig. 3a, b).

Prolonged culture of leukaemic cells may result in altered surface molecule expression (Wagers et al., 1998). In this study, two subsets of MEG-01 cells emerged that showed relative resistance to $A$. phagocytophilum infection $(\sim 20$ passages over 6-8 weeks). Infection kinetics differed in lag time from inoculation to visible infection and in the maximal percentage of infected cells as assessed by cytospin preparations $(90 \%$ infected cells decreased to $\leqslant 25 \%$ ). These cells were analysed to assess ligand modifications that best defined the susceptibility of MEG-01 cells to A. phagocytophilum infection. Flow cytometric analysis revealed an absence of PL1 binding to the resistant subpopulations (Fig. 2b). Further assessment showed moderate binding of PL2 (Fig. 2c) and CSLEX1 (Fig. 2d). The monoclonal antibody PL2 targets a membrane-proximal region of PSGL-1, whilst CSLEX1 is a sLe ${ }^{\mathrm{x}}$-specific monoclonal antibody that recognizes sialic acid in an $\alpha 2,3-$ linkage with galactose. RTPCR was performed to determine whether the absence of PL1 binding was associated with loss of the PSGL-1 transcript. PSGL-1 and appropriate fucosyltransferase (IV and VII) transcripts were present (data not shown). The low to absent PL1 binding to MEG-01 cells suggested an alteration in the PSGL-1 N terminus that normally allows PL1 to recognize the ligand. Of two MEG-01 clones that showed no PL1 binding (Fig. 2b), one achieved infection rates of up to $25 \%$, whilst the other was only $5 \%$ infected. Interestingly, the more highly infected of these two clones had a greater level of CSLEX1 binding (Fig. 2d). Together, these findings suggest that the most efficient infection of MEG-01 cells by $A$. phagocytophilum is dependent on surface expression of $\mathrm{sLe}^{\mathrm{x}}$ and PSGL-1 by the host cell. These findings parallel our recent report of a laboratory-adapted pathogen strain, $\mathrm{NCH}-$ $1 \mathrm{~A}$ (Reneer et al., 2006).

Pathogen isolates vary in their ability to accommodate different host-cell determinants. The NCH-1 strain used in this study has shown plasticity in its ability to infect cells using modified host-cell receptors (Reneer et al., 2006). Upon passage in HL60 cells that are defective for
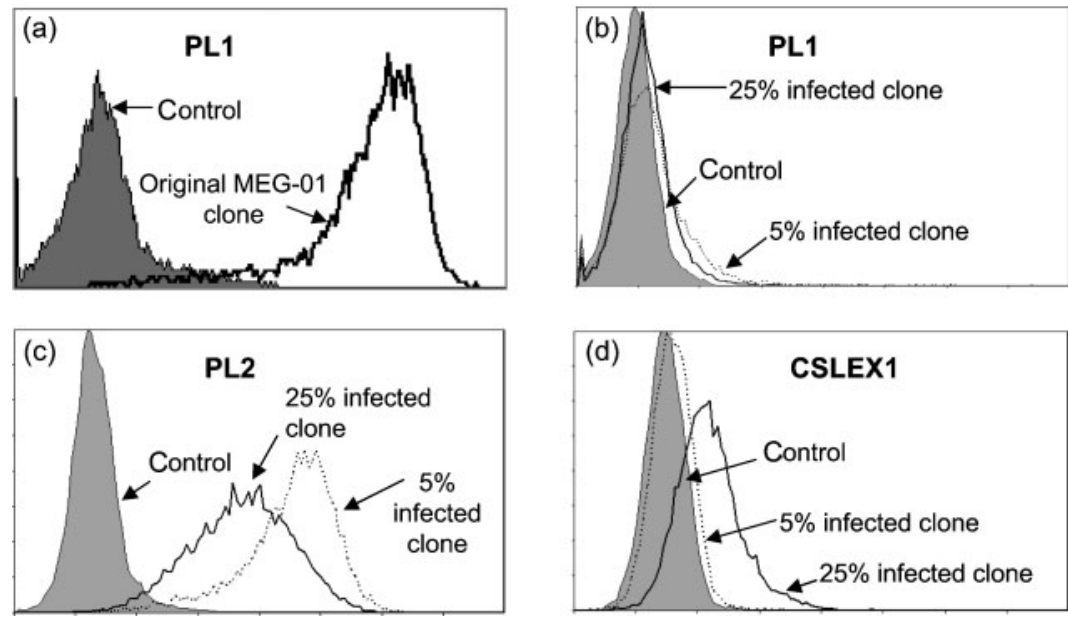

Fig. 2. A. phagocytophilum infection of MEG-01 cells is more efficient in cells that express binding sites for PL1 and CSLEX. (a) The original MEG-01 clone expressed high antibody binding of PL1. (b-d) Two clones of relatively infection-resistant MEG-01 cells were evaluated by flow cytometry to determine surface structure modifications that conferred infection resistance in MEG-01 cells. Isotype control antibodies are shown shaded in grey in each histogram. The solid black lines represent a MEG-01 clone in which $\sim 25 \%$ of cells became infected with $A$. phagocytophilum, whilst the dashed line represents a MEG-01 clone that was essentially resistant to infection (infection of $\sim 5 \%$ of cells). (b) PL1 did not bind to either cell clone. (c) PL2 bound to both clones; however, these antibodies did not define infection susceptibility as the clone with the highest resistance to infection showed higher mean channel fluorescence compared with the more susceptible clone. (d) Cells with increased infection susceptibility showed increased binding to the anti-sLe ${ }^{\mathrm{x}}$ antibody CSLEX1. 
(a)

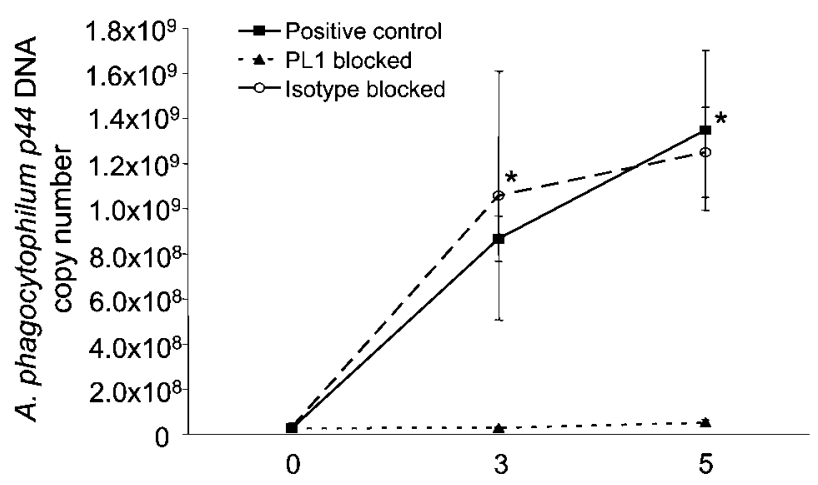

Days after $A$. phagocytophilum inoculation

(b)

\begin{tabular}{cccc}
\hline \hline \multirow{2}{*}{$\begin{array}{c}\text { Days after pathogen } \\
\text { inoculation }\end{array}$} & \multicolumn{3}{c}{ Percentage infection [mean (SEM)] } \\
\cline { 2 - 4 } & No antibody & Isotype antibody & PL1 antibody \\
\hline 0 & $5(0)$ & $5(0)$ & $5(0)$ \\
3 & $29(4.9)$ & $35(5.5)$ & $4.7(1.2)$ \\
5 & $94(5.3)$ & $91(3.6)$ & $6.3(2.1)$ \\
\hline \hline
\end{tabular}

Fig. 3. $A$. phagocytophilum infection of PSGL-1-expressing MEG-01 cells is significantly blocked by anti-PSGL-1 antibody (PL1). (a) A. phagocytophilum p44 DNA copy number was significantly lower on days 3 and 5 after pathogen inoculation in MEG-01 cells incubated with the PSGL-1 blocking antibody PL1 compared with cells incubated with no antibody or an isotype control antibody $\left({ }^{\star} P<0.05\right)$. (b) Visual inspection of the cells corroborated quantitative PCR findings. By day 5 p.i., $>90 \%$ of MEG-01 cells incubated with either no antibody or with an isotype control antibody were infected, but $<8 \%$ of MEG-01 cells incubated with PL1 were infected.

sialyltransferase and/or $\alpha 1,3$-fucosyltransferase activity and therefore cannot produce sLe ${ }^{\mathrm{x}}$, subpopulations of $\mathrm{NCH}-1$ emerge that show reduced dependency on $\mathrm{sLe}^{\mathrm{x}}$ and, consequently, PSGL-1 (Reneer et al., 2006). We have also observed this phenomenon for the HGE1 and HZ strains (Sarkar et al., 2007). Here, we demonstrated that A. phagocytophilum could invade MEG-01 cells in a $\mathrm{sLe}^{\mathrm{x}}-$ modified PSGL-1-independent manner similar to that observed for HL60 cells. However, as observed for infection of HL60 cells, optimal infection in the absence of the PL1 determinant apparently still involved $s \mathrm{se}^{\mathrm{x}}$, perhaps involving $\mathrm{sLe}^{\mathrm{x}}$ that decorates other selectin ligands expressed on MEG01 cell surfaces.

\section{Infected MEG-01 cells show decreased proliferation}

Empirically, we noted that cultured, infected MEG-01 cells appeared to decrease in number over time compared with their uninfected counterparts. Thus, proliferation of infected MEG-01 cells was examined. Infected, uninduced MEG-01 cells were reduced in number by approximately $25 \%$ compared with uninfected, uninduced cells at 24,48 and $72 \mathrm{~h}$ p.i. (data not shown). As noted by others, induction of MEG-01 cells reduces cell proliferation by promoting differentiation (Clarke et al., 2003). Compared with uninfected, induced cells, infection further reduced induced cell numbers to approximately $50 \%$ of the uninfected control cells. Although the mechanism underlying this pathogen-induced alteration was not elucidated, considerations include the induction of apoptosis or alternative disruption of cell proliferation. A. phagocytophilum induces a similar alteration in immortalized HL60 cells attributed to a dysfunctional G1-to-S transition with the failure of multiple cell-cycle and apoptosis regulatory events (Bedner et al., 1998; Hsieh et al., 1997). However, A. phagocytophilum delays apoptosis of its host neutrophil (Ge \& Rikihisa, 2006; Yoshiie et al., 2000). Therefore, given that infection-induced alterations in cell number are likely to be an in vitro phenomenon associated with pathogen growth in leukaemic cell lines, we did not pursue this alteration other than to correct for cell number while assessing proplatelet formation and platelet production.

\section{Infection does not alter proplatelet formation or PLP production}

Thrombocytopenia is a consistent characteristic of infection with A. phagocytophilum in a variety of susceptible species (Bakken et al., 1996; Borjesson et al., 2001; Lester et al., 2005; Madigan \& Gribble, 1987; Pusterla et al., 1999). Most strains of $A$. phagocytophilum do not appear to infect or interact directly with platelets (Borjesson et al., 2005a). Antibody-mediated haemolytic anaemia with concurrent thrombocytopenia has been reported to be associated with A. phagocytophilum infection in a dog (Bexfield et al., 2005), and platelet autoantibodies have been described in the serum of some human GA patients (Wong \& Thomas, 1998). None the less, in most patients and hosts, there is no evidence of antibody-mediated (adaptive) immunemediated disease. In a mouse model of infection, neither antibody-mediated destruction nor splenic sequestration of platelets was responsible for the acute thrombocytopenia seen with infection (Borjesson et al., 2001).

MEG-01 cells were utilized as a model to assess whether direct infection of MKs might lead to decreased platelet production and thereby be one mechanism of infectioninduced thrombocytopenia. Induction of MEG-01 cells with $\mathrm{CH} 11$ led to a significant increase in proplatelet formation compared with uninduced cells $(P<0.001$; Fig. $4 a-e$ and reference Clarke et al., 2003). There was no significant difference $(P=0.57)$ between proplatelet formation in infected and uninfected MEG-01 cells $24 \mathrm{~h}$ after induction (Fig. 4e). Similarly, infection did not alter spontaneous proplatelet formation in the uninduced MEG-01 cells ( $P=$ 0.29, Fig. 4e).

Platelets or PLPs are produced spontaneously by MEG-01 cells (Battinelli et al., 2001; Chuang \& Schleef, 2001; Clarke et al., 2003; Takeuchi et al., 1998). Cultured PLPs have characteristic platelet forward and side scatter as assessed by flow cytometry, and display platelet-like shape changes 

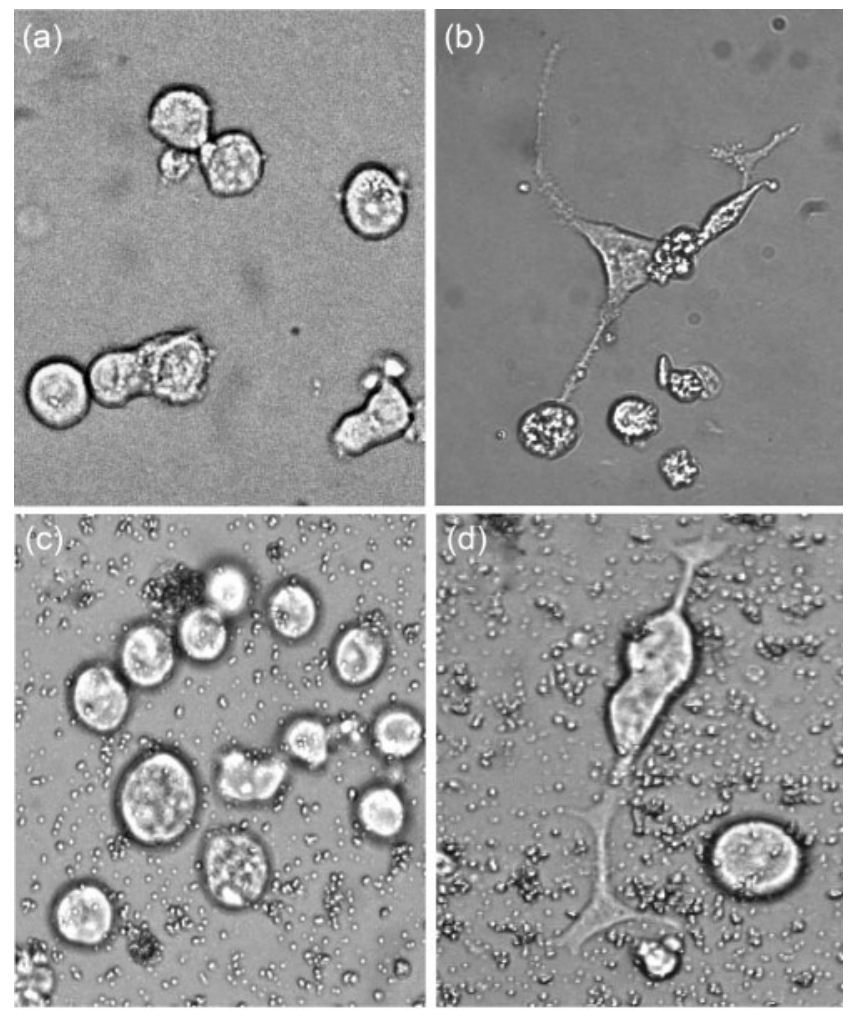

(e)

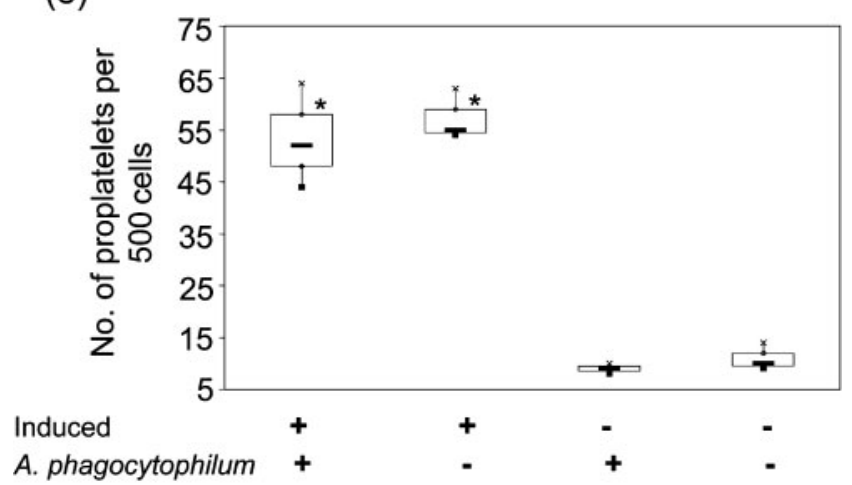

Fig. 4. Induction of differentiation and apoptosis in MEG-01 cells (using $\mathrm{CH} 11$ ) results in increased proplatelet formation in uninfected and $A$. phagocytophilum-infected MEG-01 cells. Phase-contrast micrographs (magnification $\times 400$ ) showing uninduced, uninfected MEG-01 cells (a), induced, uninfected MEG-01 cells [note the long, cellular, cytoplasmic extensions (proplatelets )] (b), uninduced, infected MEG-01 cells (c), and induced, infected MEG-01 cells (d). Induction resulted in proplatelet formation. (e) Minimum, maximum, median, and 25 and $75 \%$ quartiles of MEG01 cells expressed as number of cells with proplatelet extensions per 500 cells counted per culture well under all four conditions. The data represent three replicates. Induction led to significantly higher numbers of proplatelet extensions (asterisks indicate significant difference compared with uninduced controls); however, MEG-01 cell infection with $A$. phagocytophilum did not affect proplatelet formation. and aggregation in response to platelet agonists (Battinelli et al., 2001; Clarke et al., 2003; Takeuchi et al., 1998). They also express surface platelet receptors including $\mathrm{GPII}_{\mathrm{b}} \mathrm{III}_{\mathrm{a}}$ (Takeuchi et al., 1998). Initial evaluation in our laboratory confirmed that PLPs display characteristic forward and side scatter by flow cytometry, undergo a characteristic shift in side scatter in response to ADP and express $\mathrm{GPII}_{b} \mathrm{III}_{\mathrm{a}}$ on their surface (data not shown).

As with proplatelet formation, infection of MEG-01 cells did not significantly alter PLP formation ( $P=0.53$; Fig. 5). Early replicates of this experiment were performed with MEG-01 cells that became highly infected (at least $60 \%$ infected as assessed by cytospin preparations), whilst later replicates were performed with MEG-01 cells that were relatively resistant to A. phagocytophilum infection. The lack of effect of A. phagocytophilum infection on PLP production was consistent across these varying degrees of infection.

\section{Conclusion}

In this study, we have shown that platelet progenitors do become infected with A. phagocytophilum, and that infection susceptibility is determined by sialylated ligands similar to those that permit granulocyte infection. However, infection of MEG-01 cells, in and of itself, does not directly alter proplatelet formation and platelet production. Similarly, proplatelet formation and platelet production do not change, regardless of pathogen burden. This suggests that, although haematopoietic cells including MKs are susceptible to infection, infection-induced thrombocytopenia may not be a direct effect of intracellular pathogen. These findings are

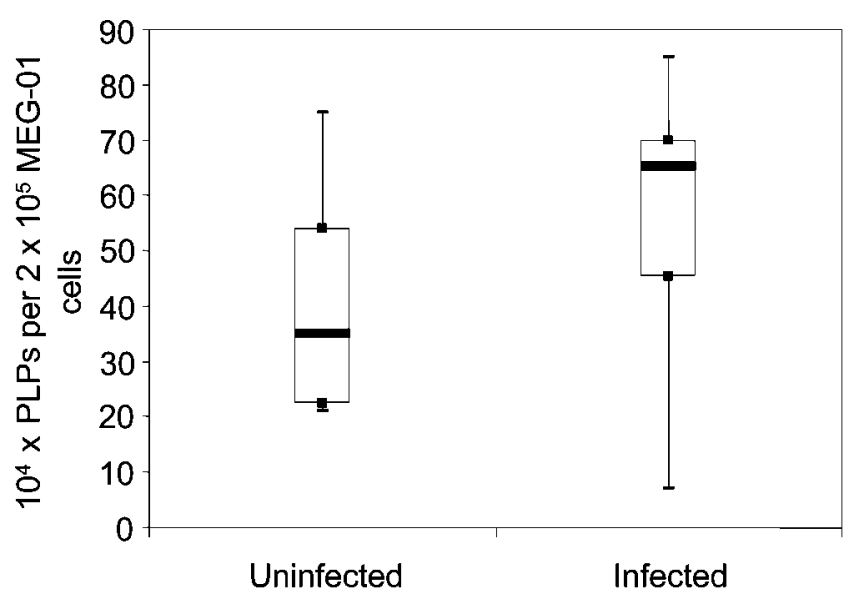

Fig. 5. Infection does not alter MEG-01 production of platelets. Depicted are the minimum, maximum, median, and 25 and $75 \%$ quartiles of the absolute numbers of platelets produced per $2 \times 10^{5}$ MEG-01 cells, as detected by flow cytometric analysis using TruCount beads, of infected and uninfected MEG-01 cells. The data represent four replicates. MEG-01 cells infected with $A$. phagocytophilum showed no significant difference in platelet production compared with uninfected cells. 
compatible with research that suggests that disease severity in the mouse is independent of pathogen burden and is related instead to activation of the innate immune system (Scorpio et al., 2004, 2005). If disrupted haematopoiesis contributes to infection-induced cytopenias, alterations in cytokine/chemokine regulation or stromal cell infection/ disruption may supersede direct pathogen effects on megakaryopoiesis, haematopoiesis and differentiation.

\section{ACKNOWLEDGEMENTS}

We gratefully acknowledge Regina Feferman, Naomi Walker and Dr Jeff Norris for technical support, and Dr Jim White for electron microscopy. This work was funded in part by a Grant-in-Aid of Research, Artistry and Scholarship from the University of Minnesota and by grant AI-51529 (DLB) from the National Institutes of Health.

\section{REFERENCES}

Bakken, J. S., Krueth, J., Wilson-Nordskog, C., Tilden, R. L., Asanovich, K. \& Dumler, J. S. (1996). Clinical and laboratory characteristics of human granulocytic ehrlichiosis. JAMA 275, 199-205.

Bakken, J. S., Aguero-Rosenfeld, M. E., Tilden, R. L., Wormser, G. P., Horowitz, H. W., Raffalli, J. T., Baluch, M., Riddell, D., Walls, J. J. \& Dumler, J. S. (2001). Serial measurements of hematologic counts during the active phase of human granulocytic ehrlichiosis. Clin Infect Dis 32, 862-870.

Battinelli, E., Willoughby, S. R., Foxall, T., Valeri, C. R. \& Loscalzo, J. (2001). Induction of platelet formation from megakaryocytoid cells by nitric oxide. Proc Natl Acad Sci U S A 98, 14458-14463.

Bedner, E., Burfeind, P., Hsieh, T. C., Wu, J. M., Aguero-Rosenfeld, M. E., Melamed, M. R., Horowitz, H. W., Wormser, G. P. \& Darzynkiewicz, Z. (1998). Cell cycle effects and induction of apoptosis caused by infection of HL-60 cells with human granulocytic ehrlichiosis pathogen measured by flow and laser scanning cytometry. Cytometry 33, 47-55.

Bexfield, N. H., Villiers, E. J. \& Herrtage, M. E. (2005). Immunemediated haemolytic anaemia and thrombocytopenia associated with Anaplasma phagocytophilum in a dog. J Small Anim Pract 46, 543-548.

Borjesson, D. L., Simon, S. I., Tablin, F. \& Barthold, S. W. (2001). Thrombocytopenia in a mouse model of human granulocytic ehrlichiosis. J Infect Dis 184, 1475-1479.

Borjesson, D. L., Simon, S. I., Hodzic, E., Ballantyne, C. M. \& Barthold, S. W. (2002). Kinetics of CD11b/CD18 up-regulation during infection with the agent of human granulocytic ehrlichiosis in mice. Lab Invest 82, 303-311.

Borjesson, D. L., Brazzell, J. L. \& Feferman, R. (2005a). Platelet dysfunction after association with Anaplasma phagocytophilum in vitro. Ann N Y Acad Sci 1063, 413-415.

Borjesson, D. L., Kobayashi, S. D., Whitney, A. R., Voyich, J. M., Argue, C. M. \& Deleo, F. R. (2005b). Insights into pathogen immune evasion mechanisms: Anaplasma phagocytophilum fails to induce an apoptosis differentiation program in human neutrophils. J Immunol 174, 6364-6372.

Chen, S. M., Dumler, J. S., Bakken, J. S. \& Walker, D. H. (1994). Identification of a granulocytotropic Ehrlichia species as the etiologic agent of human disease. J Clin Microbiol 32, 589-595.

Chuang, J. L. \& Schleef, R. R. (2001). Adenovirus-mediated expression and packaging of tissue-type plasminogen activator in megakaryocytic cells. Thromb Haemost 85, 1079-1085.
Clarke, M. C., Savill, J., Jones, D. B., Noble, B. S. \& Brown, S. B. (2003). Compartmentalized megakaryocyte death generates functional platelets committed to caspase-independent death. J Cell Biol 160, 577-587.

Dumler, J. S., Barbet, A. F., Bekker, C. P., Dasch, G. A., Palmer, G. H., Ray, S. C., Rikihisa, Y. \& Rurangirwa, F. R. (2001). Reorganization of genera in the families Rickettsiaceae and Anaplasmataceae in the order Rickettsiales: unification of some species of Ehrlichia with Anaplasma, Cowdria with Ehrlichia and Ehrlichia with Neorickettsia, descriptions of six new species combinations and designation of Ehrlichia equi and 'HGE agent' as subjective synonyms of Ehrlichia phagocytophila. Int $J$ Syst Evol Microbiol 51, 2145-2165.

Frenette, P. S., Denis, C. V., Weiss, L., Jurk, K., Subbarao, S., Kehrel, B., Hartwig, J. H., Vestweber, D. \& Wagner, D. D. (2000). P-Selectin glycoprotein ligand 1 (PSGL-1) is expressed on platelets and can mediate platelet-endothelial interactions in vivo. J Exp Med 191, 1413-1422.

Ge, Y. \& Rikihisa, Y. (2006). Anaplasma phagocytophilum delays spontaneous human neutrophil apoptosis by modulation of multiple apoptotic pathways. Cell Microbiol 8, 1406-1416.

Goodman, J. L., Nelson, C., Vitale, B., Madigan, J. E., Dumler, J. S., Kurtti, T. J. \& Munderloh, U. G. (1996). Direct cultivation of the causative agent of human granulocytic ehrlichiosis. N Engl J Med 334, 209-215.

Goodman, J. L., Nelson, C. M., Klein, M. B., Hayes, S. F. \& Weston, B. W. (1999). Leukocyte infection by the granulocytic ehrlichiosis agent is linked to expression of a selectin ligand. J Clin Invest 103, 407-412.

Herron, M. J., Nelson, C. M., Larson, J., Snapp, K. R., Kansas, G. S. \& Goodman, J. L. (2000). Intracellular parasitism by the human granulocytic ehrlichiosis bacterium through the P-selectin ligand, PSGL-1. Science 288, 1653-1656.

Hodzic, E., Feng, S., Fish, D., Leutenegger, C. M., Freet, K. J. \& Barthold, S. W. (2001). Infection of mice with the agent of human granulocytic ehrlichiosis after different routes of inoculation. J Infect Dis 183, 1781-1786.

Hsieh, T. C., Aguero-Rosenfeld, M. E., Wu, J. M., Ng, C., Papanikolaou, N. A., Varde, S. A., Schwartz, I., Pizzolo, J. G., Melamed, M. \& other authors (1997). Cellular changes and induction of apoptosis in human promyelocytic HL-60 cells infected with the agent of human granulocytic ehrlichiosis (HGE). Biochem Biophys Res Commun 232, 298-303.

Italiano, J. E., Jr, Lecine, P., Shivdasani, R. A. \& Hartwig, J. H. (1999). Blood platelets are assembled principally at the ends of proplatelet processes produced by differentiated megakaryocytes. J Cell Biol 147, 1299-1312.

Klein, M. B., Miller, J. S., Nelson, C. M. \& Goodman, J. L. (1997). Primary bone marrow progenitors of both granulocytic and monocytic lineages are susceptible to infection with the agent of human granulocytic ehrlichiosis. J Infect Dis 176, 1405-1409.

Lester, S. J., Breitschwerdt, E. B., Collis, C. D. \& Hegarty, B. C. (2005). Anaplasma phagocytophilum infection (granulocytic anaplasmosis) in a dog from Vancouver Island. Can Vet J 46, 825-827.

Li, F., Erickson, H. P., James, J. A., Moore, K. L., Cummings, R. D. \& McEver, R. P. (1996). Visualization of P-selectin glycoprotein ligand-1 as a highly extended molecule and mapping of protein epitopes for monoclonal antibodies. J Biol Chem 271, 6342-6348.

Madigan, J. E. \& Gribble, D. (1987). Equine ehrlichiosis in northern California: 49 cases (1968-1981). J Am Vet Med Assoc 190, 445-448.

Munderloh, U. G., Lynch, M. J., Herron, M. J., Palmer, A. T., Kurtti, T. J., Nelson, R. D. \& Goodman, J. L. (2004). Infection of endothelial cells with Anaplasma marginale and A. phagocytophilum. Vet Microbiol 101, 53-64. 
Ogura, M., Morishima, Y., Ohno, R., Kato, Y., Hirabayashi, N., Nagura, H. \& Saito, H. (1985). Establishment of a novel human megakaryoblastic leukemia cell line, MEG-01, with positive Philadelphia chromosome. Blood 66, 1384-1392.

Ogura, M., Morishima, Y., Okumura, M., Hotta, T., Takamoto, S., Ohno, R., Hirabayashi, N., Nagura, H. \& Saito, H. (1988). Functional and morphological differentiation induction of a human megakaryoblastic leukemia cell line (MEG-01s) by phorbol diesters. Blood 72, 49-60.

Pusterla, N., Pusterla, J. B., Braun, U. \& Lutz, H. (1999). Experimental cross-infections with Ehrlichia phagocytophila and human granulocytic ehrlichia-like agent in cows and horses. Vet Rec 145, 311-314.

Reneer, D. V., Kearns, S. A., Yago, T., Sims, J., Cummings, R. D., McEver, R. P. \& Carlyon, J. A. (2006). Characterization of a sialic acidand P-selectin glycoprotein ligand-1-independent adhesin activity in the granulocytotropic bacterium Anaplasma phagocytophilum. Cell Microbiol 8, 1972-1984.

Sarkar, M., Reneer, D. V. \& Carlyon, J. A. (2007). Sialyl-Lewis Xindependent infection of human myeloid cells by Anaplasma phagocytophilum strains HZ and HGE1. Infect Immun 75, 5720-5725.

Scorpio, D. G., Akkoyunlu, M., Fikrig, E. \& Dumler, J. S. (2004). CXCR2 blockade influences Anaplasma phagocytophilum propagation but not histopathology in the mouse model of human granulocytic anaplasmosis. Clin Diagn Lab Immunol 11, 963-968.

Scorpio, D. G., Von Loewenich, F. D., Bogdan, C. \& Dumler, J. S. (2005). Innate immune tissue injury and murine HGA: tissue injury in the murine model of granulocytic anaplasmosis relates to host innate immune response and not pathogen load. Ann N Y Acad Sci 1063, 425-428.
Takeuchi, K., Satoh, M., Kuno, H., Yoshida, T., Kondo, H. \& Takeuchi, M. (1998). Platelet-like particle formation in the human megakaryoblastic leukaemia cell lines, MEG-01 and MEG-01s. $\mathrm{Br} J$ Haematol 100, 436-444.

Telford, S. R., III, Dawson, J. E., Katavolos, P., Warner, C. K., Kolbert, C. P. \& Persing, D. H. (1996). Perpetuation of the agent of human granulocytic ehrlichiosis in a deer tick-rodent cycle. Proc Natl Acad Sci U S A 93, 6209-6214.

Wagers, A. J., Stoolman, L. M., Craig, R., Knibbs, R. N. \& Kansas, G. S. (1998). An sLex-deficient variant of HL60 cells exhibits high levels of adhesion to vascular selectins: further evidence that HECA-452 and CSLEX1 monoclonal antibody epitopes are not essential for high avidity binding to vascular selectins. J Immunol 160, 5122-5129.

White, J. G. (2005). Platelets are covercytes, not phagocytes: uptake of bacteria involves channels of the open canalicular system. Platelets 16, 121-131.

Wong, S. J. \& Thomas, J. A. (1998). Cytoplasmic, nuclear, and platelet autoantibodies in human granulocytic ehrlichiosis patients. J Clin Microbiol 36, 1959-1963.

Yago, T., Leppanen, A., Carlyon, J. A., Akkoyunlu, M., Karmakar, S., Fikrig, E., Cummings, R. D. \& McEver, R. P. (2003). Structurally distinct requirements for binding of $\mathrm{P}$-selectin glycoprotein ligand-1 and sialyl Lewis $\mathrm{x}$ to Anaplasma phagocytophilum and P-selectin. J Biol Chem 278, 37987-37997.

Yoshiie, K., Kim, H. Y., Mott, J. \& Rikihisa, Y. (2000). Intracellular infection by the human granulocytic ehrlichiosis agent inhibits human neutrophil apoptosis. Infect Immun 68, 1125-1133. 